\title{
UNIVERSIDADE E A EXTENSÃO UNIVERSITÁRIA: A VISÃO DOS MORADORES DAS COMUNIDADES CIRCUNVIZINHAS
}

\author{
Marcelo Costa Fernandes* \\ Lucilane Maria Sales da Silva** \\ Ana Larissa Gomes Machado*** \\ Thereza Maria Magalhães Moreira****
}

RESUMO: A universidade é uma instituição criada para atender às necessidades do país. Uma das estratégias que a universidade utiliza para a formação de um profissional cidadão é baseada na extensão universitária. Objetivou-se no estudo investigar a relação atual existente entre uma universidade e as comunidades circunvizinhas a partir da visão dos seus moradores. A pesquisa é de natureza descritiva com abordagem qualitativa. Foi realizada no município de Fortaleza-CE. A população da pesquisa foi constituída por moradores da comunidade. O estudo teve início após a aprovação do projeto pelo Comitê de Ética em Pesquisa. Os resultados foram divididos em cinco categorias para uma melhor organização da discussão dos resultados. Percebeu-se que a extensão universitária possui uma função essencial no ensino superior brasileiro principalmente para a formação de uma integração entre a comunidade e a universidade, objetivando, com isso, uma maior transformação de nossa realidade social.

Palavras-chave: Universidade; Ensino; Extensão Universitária; Cidadania; Responsabilidade Social.

\footnotetext{
* Mestre em Cuidados Clínicos em Saúde pela Universidade Estadual do Ceará (UECE) e Participante do Laboratório de Pesquisas e de Práticas Coletivas em Saúde (LAPRACS). E-mail: celo_cf@hotmail.com

* *Doutora em Enfermagem pela Universidade Federal do Ceará (UFC) e Professora da Universidade Estadual do Ceará (UECE). E-mail: lucilanemaria@yahoo.com.br

*** Doutoranda em Enfermagem pela Universidade Federal do Ceará (UFC). E-mail: analarissa2001@yahoo.com.br

* * * Doutora em Enfermagem pela Universidade Federal do Ceará (UFC); Professora da Universidade Estadual do Ceará (UECE) e Pesquisadora do Conselho Nacional de Desenvolvimento Científico e Tecnológico (CNPq). E-mail: tmmmoreira@yahoo.com.br
} 


\section{UNIVERSITY AND UNIVERSITY EXTENSION: THE VIEW OF THE RESIDENTS FROM SURROUNDING COMMUNITIES}

ABSTRACT: The university is an institution created to meet the needs of the country. One of the strategies that the university uses to train a professional citizen is based on the university extension. The purpose of this study was to investigate the existing relationship between a university and its surrounding communities from the perspective of its inhabitants. Descriptive qualitative methodology was used in the research. It was held in Fortaleza, State of Ceara. The research population consisted of community residents. The study began after the project was approved by the Research Ethics Committee. Results were divided into five categories to better organize the discussion. It was possible to observe that university extension plays a key role in the Brazilian higher education, mainly in the formation of integration between community and university, aiming at a major transformation of our social reality.

Keywords: University; Teaching; University Extension; Citizenship; Social Responsibility.

\section{INTRODUÇÃO}

A universidade é um espaço que possibilita a agregação de inúmeros saberes heterogêneos. É a base para a formação dos estudantes, para uma carreira profissional e também para estender os limites do conhecimento, intensificar a criatividade e moldar a identidade de uma nação.

Algumas das maiores virtudes e expressões do compromisso social da universidade são identificadas por meio de suas ações de pesquisa, ensino e extensão, consideradas atividades básicas do ensino superior. $\mathrm{O}$ exercício de tais funções é solicitado como dado de excelência na graduação, fundamentalmente voltado à formação de um profissional cidadão relacionado com a apropriação e produção do conhecimento científico e compromissado ainda com a realidade social (MENEZES NETO, 1983).

Uma das estratégias que a universidade utiliza para a formação de um profissional cidadão é baseada na efetiva relação recíproca do acadêmico com a comunidade, seja para se situar historicamente, para se identificar culturalmente ou para referenciar sua formação com os problemas que um dia terá que enfrentar (BRASIL, 1999).

A relação mais direta entre universidade e comunidade é proporcionada pela extensão universitária, entendida como um processo interdisciplinar educativo, cultural, científico e político, que, sob o princípio da indissociabilidade, promove a interação transformadora entre universidade e 
outros setores da sociedade (FÓRUM DE PRÓ-REITORES DE EXTENSÃO DAS UNIVERSIDADES PÚBLICAS BRASILEIRAS, 2010). Convergindo com esse pensamento, Gurgel (1986) aponta as atividades desenvolvidas pela extensão universitária como o elemento de ligação entre as instituições de ensino superior e os demais setores da sociedade. A pesquisa também possui relação com a comunidade, por meio da descoberta de remédios, vacinas, tratamentos, desenvolvimento de novas tecnologias e produtos, além de procurar soluções para os problemas que afetam a sociedade. E o ensino, por sua vez, também propicia uma maior qualificação dos sujeitos, capacitando-os para as lutas sociais e consequentes transformações da comunidade.

Segundo Saraiva (2007), a extensão possibilita ao acadêmico a experiência de vivências significativas que lhe proporciona reflexões acerca das grandes questões da atualidade e, com base na experiência e nos conhecimentos produzidos e acumulados, o desenvolvimento de uma formação compromissada com as necessidades nacionais, regionais e locais, considerando-se a realidade brasileira. Os três fundamentos da universidade, isto é, ensino, pesquisa e extensão, propiciam experiências a discentes e docentes, mas a extensão faz a associação paralela imediata entre o conhecimento científico e o popular.

A extensão trabalha com o conhecimento e este, como salienta Freire (1992), exige uma presença curiosa do sujeito em face do mundo. Solicita sua ação transformadora sobre a realidade. Demanda busca contínua. Implica invenção e reinvenção. Reivindica a reflexão crítica de cada um sobre o ato mesmo de conhecer, pelo qual se reconhece conhecendo e, ao reconhecer assim, percebe o "como" de seu conhecer e os condicionamentos a que está seu ato submetido. Conhecer é ocupação de sujeitos e não de objetos. E é como sujeito e apenas como sujeito, que o homem pode realmente conhecer. Por isso mesmo é que, no processo de aprendizagem, somente aprende verdadeiramente aquele que se apossa do aprendido, transformando-o em apreendido, com o que pode, por isso mesmo, reinventá-lo. Pelo contrário, aquele que é sobrecarregado por outros conteúdos cuja inteligência não percebe, de conteúdos que contradizem a forma própria de estar em seu mundo, sem que seja posto em desafio, não aprende.

Entretanto, ao longo da sua existência, a universidade sempre tem dispensado um tratamento diferenciado à extensão. $\mathrm{O}$ ensino, por muito 
tempo, foi tratado de forma dicotomizada da pesquisa e da extensão, embora, em algumas instituições, a pesquisa tenha recebido uma atenção especial enquanto a extensão ocupava um espaço mais voltado para ações pontuais, com poucas verbas para a sua realização (MONTE, 2005).

Há algum tempo, a pesquisa assume um papel importante nas instituições públicas de ensino superior, recebendo o incentivo do governo através de vários órgãos, enquanto a extensão permanece sem o devido reconhecimento nessa história. Com a crise e a política de Estado mínimo na atualidade, a universidade pública é afetada pela retração dos incentivos econômico e financeiros direcionados à educação, sendo a extensão universitária, por sua vez, afetada de forma mais contundente (MONTE, 2005).

Com isso, o ensino deve ser estimulado e trabalhado simultaneamente com a pesquisa e a extensão nas universidades, pois o ensino meramente transmissivo quebra o elo da indissociabilidade, comprometendo a qualidade do processo de aprendizagem. Trabalho com grupos populares da comunidade deve existir, para que se possa construir uma cultura acadêmica com espaços de integração entre a sociedade e a universidade.

Portanto, a universidade deve estar inserida permanentemente na comunidade, realizando a troca de experiências, assimilando, revendo valores e prioridades que permitam que a população se identifique como sujeito de sua própria história, proporcionando consequentes mudanças das condições de vidas, superando, assim, problemas sociais encontrados na própria comunidade (LIMA, 2003).

Freire (1979) define a natureza humana, eminentemente como de reflexão e relação. Só a pessoa humana é capaz de objetivar a realidade e refletir a respeito dela, cabe à universidade, enquanto órgão formador, estimular a construção de espaços e ambientes capazes de propiciar momentos de reflexão dessa realidade.

Parte-se do princípio de que a formação do acadêmico é tomada como fundamento do processo educativo implementado na universidade, uma vez que contribuirá para sua compreensão como ser socialmente responsável e livre, capaz de refletir sobre o vivido e o aprendido em sala de aula e outros espaços, como na comunidade, que vão construindo cotidianamente sua identidade pessoal e profissional alicerçadas na busca do saber ser, saber fazer e saber aprender, ou seja, na formação de suas competências. 
Diante das explanações feitas sobre a importância e das dificuldades da extensão universitária, questiona-se: quais as relações atuais existentes entre uma universidade nordestina e a comunidade circunvizinha ao seu território no âmbito da extensão universitária?

Entende-se que esta proposta poderá gerar possibilidades de estabelecer parcerias entre as universidades e os demais setores da sociedade para a construção de um projeto social que traga dignidade à vida de todas as pessoas, sendo, igualmente, capaz de transformar conhecimento em sabedoria e de ser um estímulo de vida à comunidade e ao ensino acadêmico.

O conhecimento produzido a partir deste estudo ainda poderá contribuir com sugestões para o desenvolvimento e ampliação das ações realizadas na universidade em parceria com a comunidade, colaborando para que a universidade possa exercer seu papel social e reforçar, em específico, a geração de tecnologias, saberes e inovações que possam estar a serviço da comunidade, reconhecendo-a como sujeito do processo.

\section{METODOLOGIA}

A pesquisa é de natureza descritiva com abordagem qualitativa. Foi realizada no município de Fortaleza-CE, em específico, na Secretaria Executiva Regional (SER) IV. A SER IV apresenta uma área territorial de $34.272 \mathrm{~km}^{2}$, abrangendo 19 bairros, com perfil socioeconômico caracterizado por diversos serviços, com uma das maiores e mais antigas feiras livres da cidade, além de vários corredores comerciais. São bairros desta área: São José Bonifácio; Benfica; Fátima; Jardim América; Damas; Parreão; Bom Futuro; Vila União; Montese; Couto Fernandes; Pan Americano; Demócrito Rocha; Itaoca; Parangaba; Serrinha; Aeroporto; Itaperi; Dendê e Vila Pery. Sua população é de aproximadamente 305 mil habitantes. Foram escolhidos os bairros Itaperi, com 22.563 habitantes, e Serrinha, com 28.770 habitantes, por serem as comunidades circunvizinhas à Universidade Estadual do Ceará-UECE, campus do Itaperi (INSTITUTO BRASILEIRO DE GEOGRAFIA E ESTATÍSTICA, 2010). A população do estudo foi constituída por moradores dessas comunidades.

A amostra foi obtida de maneira aleatória, com visitas às residências circunvizinhas à universidade, isto é, no bairro do Itaperi e Serrinha. Destaca-se que os bairros em questão possuem espaços onde frequentemente 
são realizadas atividades na comunidade por universitários, como posto de saúde, escolas e praças.

O número de participantes não foi previamente estabelecido, uma vez que foi levada em consideração a saturação teórica, ou seja, a coleta de dados se encerrou quando as experiências e percepções dos novos participantes estavam se repetindo, ou seja, optou-se por concluir a coleta a partir do momento em que as novas informações repassadas pouco contribuiriam ao material já obtido (FONTANELLA; RICAS; TURATO, 2008). Ao final foi totalizado um número de vinte e seis entrevistas.

A coleta de informações foi realizada mediante entrevista semiestruturada, realizada individualmente, constando de cinco questões abertas norteadoras sobre o assunto e respeitando a livre expressão de suas representações. Esse tipo de entrevista possibilitou ao entrevistado discorrer sobre o tema proposto, sem respostas ou condições pré-estabelecidas pelo pesquisador. Assim, julga-se sua utilização adequada, pois possibilitou obter, por meio do depoimento de cada um dos entrevistados, o conteúdo pretendido e necessário para a análise e interpretação à luz da literatura científica e dos objetivos formulados (MINAYO, 2007). As entrevistas foram gravadas com a aquiescência dos entrevistados.

Antes de começar a transcrição, as entrevistas foram ouvidas várias vezes, visando à compreensão das falas, em seguida, realizou-se o registro literal de todos os depoimentos orais.

Para proceder à ordenação e organização dos dados empíricos, produzidos nas entrevistas semiestruturadas, junto aos moradores das comunidades, selecionados para esta investigação, recorre-se ao processo metodológico do Discurso do Sujeito Coletivo (DSC), que é uma ferramenta que viabiliza a representação do pensamento de um determinado grupo. É uma proposta metodológica que propõe a soma das ideias não de maneira numérica, mas operacionalizando de forma metodológica a expressão do pensamento coletivo por meio do discurso. É um processo complexo, que resulta, ao final, num conjunto de discursos subdividido em vários momentos, efetuados por meio de uma série de operações realizadas sobre o material verbal coletado na pesquisa (LEFÈVRE; LEFÈVRE, 2005).

O DSC tem como finalidade, enquanto estratégia metodológica, visualizar com maior clareza uma dada representação que surge a partir de uma forma concreta do pensamento nos discursos dos sujeitos. Sua elaboração, 
como foi destacada, segue uma lapidação analítica de decomposição e é caracterizado, inicialmente, pela escolha das Expressões-chave $(\mathrm{ECH})$, das principais Ideias Centrais (IC) presentes nos discursos individuais e constituídos, posteriormente, em um único discurso, dando a ideia de que todos estão sendo representados por uma única pessoa (PAULA; PALHA; PROTTI, 2004).

As ECH podem ser definidas como fragmentos, trechos ou transcrições literais do discurso que devem ser destacadas pelo pesquisador e que revelam a essência de todo o conjunto do discurso observado. Apresentam-se, portanto, como uma espécie de comprovação e justificativa da existência da IC (LEFÈVRE; LEFÈVRE, 2005).

A IC é um nome ou expressão linguística que revela e descreve, da maneira mais sintética e precisa possível, o sentido de cada um dos discursos analisados, e de cada conjunto homogêneo de ECH que irá dar origem, posteriormente, ao DSC. Essas IC podem expressar descrições diretas do sentido do depoimento, revelando "o que foi dito", ou descrições indiretas que apresentam o tema do depoimento "ou sobre o que" seu sujeito enunciador fala (LEFÈVRE; LEFÈVRE, 2005).

Segundo Lefèvre e Lefèvre (2005), o DSC é um discurso síntese redigido na primeira pessoa do singular e composto pelas expressões-chave que possuem a mesma ideia central, é a principal dentre as figura metodológicas aqui discutidas, sendo também uma proposta de organização e tabulação de dados qualitativos de natureza verbal.

Logo, o DSC representa um expediente ou recurso metodológico destinado a tornar mais claras e expressivas as representações sociais, permitindo que um determinado grupo social possa ser visto como autor e emissor de discursos comuns, compartilhando entre seus membros. Com o sujeito coletivo, os discursos não se anulam ou se reduzem a uma categoria comum unificadora, já que o que se busca fazer é precisamente o inverso, ou seja, reconstruir, com pedaços de discursos individuais, como em um quebra-cabeça, tantos discursos síntese quantos se julgue necessário para expressar uma dada "figura", um dado pensar ou uma representação social sobre um fenômeno (LEFÈVRE; LEFÈVRE, 2005).

A investigação teve início após a aprovação do projeto pelo Comitê de Ética em Pesquisa da Universidade Estadual do Ceará-UECE sob o processo de no 07394164-6. FR 157324. Os componentes éticos e 
legais estão presentes em todas as fases da pesquisa, em conformidade com a Resolução 196/96 do Conselho Nacional de Saúde (BRASIL, 1996) que dispõe sobre as diretrizes e normas regulamentadoras de pesquisas envolvendo seres humanos.

Foi solicitada a assinatura do Termo de Consentimento Livre e Esclarecido aos sujeitos do estudo, informando a garantia do anonimato e a liberdade em participar ou retirar seu consentimento em qualquer fase da pesquisa.

\section{APRESENTAC̣ÃO E DISCUSSÃO DOS RESULTADOS}

Os dados demonstrados a seguir são referentes a vinte e seis moradores das comunidades. Não é objetivo extenuar a discussão do DSC, mas sim apresentar e identificar os pontos considerados de relevância em relação aos objetivos propostos no estudo.

De acordo com as perguntas norteadoras da entrevista do estudo, os resultados da pesquisa foram divididos em cinco categorias para uma melhor organização da discussão dos resultados: Papel da universidade; Atividades de extensão desenvolvidas pela universidade; Ações de extensão que a universidade poderia realizar; Dificuldades enfrentadas pela universidade para a realização de ações de extensão; e Facilidades enfrentadas pela universidade para a realização de ações de extensão.

\section{PAPEL DA UNIVERSIDADE}

Conhecer o papel da Universidade é uma etapa importante no processo de compreensão do seu compromisso social. Neste sentido, a primeira pergunta dirigida aos sujeitos do estudo tentou resgatar o pensamento e conhecimento destes sobre o assunto. O Quadro 1 destaca as expressões-chave, ideias centrais e respectivos discursos.

A primeira IC dos moradores das comunidades (Quadro 1): “Não sei qual o papel da universidade". No DSC (1), há destaque para o desconhecimento por parte dos moradores da comunidade sobre o papel da universidade. Um trecho da fala chama a atenção para esse ponto: “[...] 
sempre passo em frente da universidade, mas não sei o que eles fazem ali dentro, nunca tive oportunidade para entrar e conhecer [...]". O discurso apresenta a atual realidade do ensino superior brasileiro, pois demonstra que a universidade está fisicamente próxima da comunidade, porém há ainda

\author{
Quadro 1 \\ Expressões-chave, Ideia central e Discurso do Sujeito Coletivo \\ de vinte e seis moradores das comunidades. Fortaleza-CE, Brasil, 2009
}

Qual o papel da universidade?

\begin{tabular}{|c|c|c|}
\hline $\begin{array}{c}\text { Expressões-chave (1) } \\
\text { “[...] assim sabe, eu não } \\
\text { sei explicar o papel da } \\
\text { universidade [...]" } \\
\text { “[...] na verdade não tenho } \\
\text { conhecimento sobre o papel } \\
\text { da universidade [...]" } \\
\text { “[...] não sei responder, } \\
\text { sempre passo em frente, } \\
\text { mas não sei o que eles } \\
\text { fazem ali dentro, nunca } \\
\text { entrei e conheci [...]" } \\
\text { "[...] não sei falar qual } \\
\text { o verdadeiro papel da } \\
\text { universidade [...]” }\end{array}$ & $\begin{array}{c}\text { Ideia Central (1) } \\
\text { Não sei qual o papel da } \\
\text { universidade. }\end{array}$ & $\begin{array}{l}\text { Discurso do Sujeito Coletivo (1) } \\
\text { Pra falar a verdade, eu não tenho } \\
\text { conhecimento nenhum, sempre passo } \\
\text { em frente da universidade, mas não sei } \\
\text { o que eles fazem ali dentro, nunca tive } \\
\text { oportunidade para entrar e conhecer, } \\
\text { assim não sei qual o verdadeiro papel } \\
\text { da universidade. }\end{array}$ \\
\hline $\begin{array}{c}\text { Expressões-chave (2) } \\
\text { "[...] papel da universidade } \\
\text { é muito importante né? Eles } \\
\text { atendem bastante a nossa } \\
\text { comunidade no posto [...]" } \\
\text { "[...] o pessoal da } \\
\text { universidade dá muita } \\
\text { assistência pra nós, quando } \\
\text { alguém fica doente eles nos } \\
\text { atendem [...]" } \\
\text { "[...] eles fazem consultas, } \\
\text { os estudantes e } \\
\text { professores, acho muito } \\
\text { importante esse papel da } \\
\text { universidade, de ficar nos } \\
\text { atendendo [...]" }\end{array}$ & $\begin{array}{c}\text { Ideia Central (2) } \\
\text { Dá assistência aos } \\
\text { moradores. }\end{array}$ & $\begin{array}{l}\text { Discurso do Sujeito Coletivo (2) } \\
\text { O papel da universidade é muito } \\
\text { importante. Porque o pessoal da } \\
\text { universidade dá muita assistência } \\
\text { para os moradores da comunidade } \\
\text { quando estão doentes. Quando } \\
\text { alguém fica doente é só ir ao posto } \\
\text { que os estudantes e professores da } \\
\text { universidade nos atende. }\end{array}$ \\
\hline
\end{tabular}




\section{Quadro 1}

Continuação...

Qual o papel da universidade?

\begin{tabular}{|c|c|c|}
\hline $\begin{array}{l}\text { Expressões-chave (3) } \\
\text { "[...] no meu ponto de } \\
\text { vista, o principal papel } \\
\text { é formar profissionais } \\
\text { cidadãos, profissionais com } \\
\text { compromisso de atuarem } \\
\text { dentro da comunidade [...]" } \\
\text { "[...] acho que o mais } \\
\text { importante é a formação, } \\
\text { formação de cidadãos, que } \\
\text { conheçam a nossa realidade } \\
\text { social, realidade que eles } \\
\text { futuramente farão parte } \\
\text { [...]” } \\
\text { "[...] formar profissionais } \\
\text { que procurem formas de } \\
\text { solucionar os problemas } \\
\text { sociais, os problemas da } \\
\text { comunidade [...]" }\end{array}$ & $\begin{array}{c}\text { Ideia Central (3) } \\
\text { Formação de profissionais } \\
\text { cidadãos. }\end{array}$ & $\begin{array}{l}\text { Discurso do Sujeito Coletivo (3) } \\
\text { No meu ponto de vista, a universidade } \\
\text { tem um papel importante na formação } \\
\text { de profissionais cidadãos, profissionais } \\
\text { mais voltados para uma atuação } \\
\text { dentro da comunidade, conhecendo } \\
\text { mais a realidade social e contribuindo } \\
\text { na busca de soluções para os } \\
\text { problemas da comunidade, em que ele } \\
\text { vai se inserir futuramente. }\end{array}$ \\
\hline
\end{tabular}

enormes lacunas separando-as. Essas são caracterizadas pela ausência de abertura entre a universidade e a comunidade, comunicação deficiente e pouca integração, impossibilitando um processo de construção de conhecimento em parceria e limitando a universidade aos muros acadêmicos.

A segunda IC (Quadro 1): "Dá assistência aos moradores". Percebe-se que a relação da universidade com a comunidade encontra-se ainda bastante restrita a práticas assistenciais de acordo com a fala dos moradores: “[...] o pessoal da universidade dá muita assistência para os moradores da comunidade [...] quando alguém fica doente é só ir ao posto que os estudantes e professores da universidade nos atende". A proposta de extensão universitária indica um trabalho de relacionamento entre a universidade e a comunidade, capaz de desenvolver um conhecimento mútuo, no qual a sociedade levasse o saber popular aos docentes e discentes e estes compartilhassem o saber científico. Entretanto, esse ambiente de difusão do saber, que deveria ser o foco da extensão é, em geral, transformado 
em atividades assistenciais, realizadas simplesmente para complementar o aprendizado dos universitários (MELO NETO, 2004).

Nota-se, na terceira IC (Quadro 1): "Formação de profissionais cidadãos", uma nova visão com relação ao papel da universidade, um papel não mais limitado apenas para a formação de profissionais técnicos e voltados para as necessidades e demandas do mercado de trabalho. Mas uma universidade capaz de formar profissionais com atitude de não aceitação da realidade em que se encontram e que buscam poder transformá-la. Profissionais críticos, competentes e capazes de propor um novo tipo de sociedade mais justa e mais humana. Profissionais cidadãos que possam se envolver com as preocupações sociais e que considerem as expectativas, necessidades e anseios da comunidade. Supõem ainda responsabilidade social, comportamento ético e exercício de cidadania. Portanto, a universidade promove a formação de profissionais que se percebam não como um ser isolado, mas, sim, como alguém que vive, interfere e sofre influências de um meio do qual faz parte (LIMA, 2003).

\section{ATIVIDADES DE EXTENSÃO DESENVOLVIDAS PELA UNIVERSIDADE}

No intuito de obter informações sobre as atividades que a universidade desenvolve na comunidade, foi possível a elaboração de ICs que possibilitaram a construção do material discursivo demonstrado no Quadro 2.

Primeira IC dos moradores das comunidades (Quadro 2): “Eu nunca nem ouvi falar". A extensão universitária encontra-se ainda fragilizada na questão da realização de aproximação e desenvolvimento de atividades dentro da própria comunidade, não chegando a envolver boa parte dos moradores, conforme é evidenciado na fala a seguir: “[...] nunca nem vi o pessoal da universidade andando na comunidade, pelos menos nunca fui informado, [...] nunca vi nenhuma atividade".

A segunda IC (Quadro 2) aborda o assistencialismo da extensão universitária: "Fazem bastante atendimento".

A população, neste ambiente, é utilizada como justificativa para praticar a teoria ensinada nas salas de aula. Essa deformação da extensão oculta, quase sempre uma intenção caritativa, na qual universitários, principalmente os estudantes da área da saúde, oferecem serviços semiprofissionais à 
comunidade, acreditando exercer um "favor" por esse serviço gratuito (BUFFA; CANALES, 2007). Eles não lembram que é essa sociedade que mantém as universidades públicas brasileiras funcionando através dos impostos pagos, não existindo assim prestação de favor (SAVIANI, 1981).

Quando existe essa ideia de prestação de favores, o trabalho da extensão universitária torna-se assistencialista. Assistencialismo é compreendido como prestar ajuda a alguém, o que gera dependência, sem que haja aprendizado em ambas as partes (BUFFA; CANALES, 2007).

\section{Quadro 2}

Expressões-chave, Ideia central e Discurso do Sujeito Coletivo de vinte e seis moradores das comunidades. Fortaleza-CE, Brasil, 2009

\section{Quais atividades de extensão a universidade desenvolve neste espaço?}

\begin{tabular}{|c|c|c|}
\hline $\begin{array}{l}\text { Expressões-chave (1) } \\
\text { “[...] e tem mesmo? Eu } \\
\text { mesma nunca vi [...]" } \\
\text { “[...] eu acho que não tem, } \\
\text { sabe por quê? Porque } \\
\text { eu nunca vi o pessoal da } \\
\text { universidade andando por } \\
\text { aqui [...]" } \\
\text { “[...] nunca me falaram se } \\
\text { existe atividades aqui, e } \\
\text { também nunca ouvi falar e } \\
\text { também nem vi nada [...]” }\end{array}$ & $\begin{array}{c}\text { Ideia Central (1) } \\
\text { Eu nunca nem ouvi falar. }\end{array}$ & $\begin{array}{l}\text { Discurso do Sujeito Coletivo (1) } \\
\text { E tem? Porque eu nunca nem vi o } \\
\text { pessoal da universidade andando na } \\
\text { comunidade, pelo menos nunca fui } \\
\text { informado e nem ouvi falar, nunca } \\
\text { vi nenhuma atividade. }\end{array}$ \\
\hline $\begin{array}{l}\text { Expressões-chave (2) } \\
\text { “[...] o que eu sei, é que } \\
\text { a universidade faz várias } \\
\text { atividades da unidade } \\
\text { de saúde, atendendo os } \\
\text { moradores daqui [...]” } \\
\text { “[...] é as consultas né? Eu já } \\
\text { fui atendida por estudantes } \\
\text { várias vezes [...]” } \\
\text { „[...] fazem as vacinações } \\
\text { e durante os atendimentos } \\
\text { fazem também prevenção de } \\
\text { câncer [...]” }\end{array}$ & $\begin{array}{c}\text { Ideia Central (2) } \\
\text { Fazem bastante atendimento. }\end{array}$ & $\begin{array}{l}\text { Discurso do Sujeito Coletivo (2) } \\
\text { Eu sei que a universidade tem } \\
\text { atividades na unidade de saúde, } \\
\text { os estudantes fazem bastante } \\
\text { atendimento, exame de prevenção } \\
\text { de câncer e vacinação. }\end{array}$ \\
\hline
\end{tabular}




\section{Quadro 2}

Continuação...

Quais atividades de extensão a universidade desenvolve neste espaço?

\begin{tabular}{|c|c|c|}
\hline $\begin{array}{l}\text { Expressões-chave (3) } \\
\text { “[...] eu só conheço } \\
\text { as atividades que são } \\
\text { desenvolvidas pelos } \\
\text { acadêmicos, as principais } \\
\text { e até que gosto muito de } \\
\text { participar, são as atividades } \\
\text { de educação em saúde [...]" } \\
\text { "[...] os estudantes da } \\
\text { universidade, realizam } \\
\text { várias atividade educativas, } \\
\text { atividades estas voltas mais } \\
\text { para a questão da saúde [...]” } \\
\text { "[...] as atividades mais } \\
\text { comuns são as atividades de } \\
\text { educação em saúde, através } \\
\text { de palestras, oficinas, aulas } \\
\text { e terapias para os moradores } \\
\text { da comunidade [...]” }\end{array}$ & $\begin{array}{c}\text { Ideia Central (3) } \\
\text { Atividades de educação em } \\
\text { saúde. }\end{array}$ & $\begin{array}{l}\text { Discurso do Sujeito Coletivo (3) } \\
\text { As atividades que eu conheço } \\
\text { desenvolvidas pela universidade } \\
\text { são realizadas principalmente por } \\
\text { meio dos acadêmicos. Eles realizam } \\
\text { várias atividades de educação } \\
\text { em saúde através de palestras, } \\
\text { oficinas, aulas e terapias para os } \\
\text { moradores da comunidade. }\end{array}$ \\
\hline $\begin{array}{l}\text { Expressões-chave (4) } \\
\text { “[...] eu já participei de } \\
\text { algumas, participei das } \\
\text { atividades esportivas, eu } \\
\text { jogava basquete e a minha } \\
\text { irmã jogava vôlei [...]” } \\
\text { “[...] os estudantes } \\
\text { da educação física da } \\
\text { universidade, faziam várias } \\
\text { atividades esportivas aqui } \\
\text { [...]” } \\
\text { “[...] que eu sei e que até } \\
\text { fizeram um dia desses, foi } \\
\text { tipo campanhas de saúde } \\
\text { [...]” } \\
\text { “[...] os estudantes da saúde, } \\
\text { sempre vêm e falam sobre } \\
\text { vários assuntos, o último que } \\
\text { participei foi sobre DST e } \\
\text { dengue [...]” }\end{array}$ & $\begin{array}{c}\text { Ideia Central (4) } \\
\text { Atividades esportivas e } \\
\text { campanhas educativas sobre } \\
\text { saúde. }\end{array}$ & $\begin{array}{l}\text { Discurso do Sujeito Coletivo (4) } \\
\text { Realizam algumas atividades } \\
\text { esportivas, como as escolinhas de } \\
\text { basquete e vôlei, desenvolvidas } \\
\text { pelos estudantes da educação } \\
\text { física, e campanhas educativas } \\
\text { sobre saúde, falando alguns } \\
\text { assuntos como DST e dengue, } \\
\text { desenvolvidas pelos estudantes da } \\
\text { área da saúde. }\end{array}$ \\
\hline
\end{tabular}


Freire (1969) discute em sua obra a substituição da expressão extensão por comunicação para demonstrar que esse trabalho deve ser $\mathrm{o}$ ato do diálogo entre a sociedade e toda a comunidade acadêmica. $\mathrm{O}$ educador defende ainda que, sem essa comunicação, a universidade acaba por furtar da comunidade as condições necessárias para que possa assumir suas responsabilidades, o que é fundamental e também imprescindível ao crescimento dos sujeitos.

A terceira e a quarta ICs demonstradas no (Quadro 2) enfocam algumas atividades educativas realizada pela universidade: "Atividades de educação em saúde" e "Atividades esportivas e campanhas educativas sobre saúde".

Atividades de educação em saúde, como atividades esportivas e oficinas, realizadas pela comunidade acadêmica são essenciais para a promoção da saúde, uma vez que, por seu intermédio, os moradores da comunidade, sujeitos do seu processo de aprendizagem, podem ser motivados a transformarem suas vidas, sendo esta premissa um dos objetivos deste tipo de atividades (TREZZA; SANTOS; SANTOS, 2007).

A educação popular caracteriza-se por uma filosofia emancipatória dos sujeitos, a partir da sensibilização dos seus direitos, envolvendo aspectos sociais, culturais e políticos. Logo, a educação popular em saúde tem como ponto de partida despertar o sentimento de cidadania da comunidade (PEREIRA et al., 2007).

\section{AC̣ÕES DE EXTENSÃO QUE A UNIVERSIDADE PODERIA REALIZAR}

Consultando a opinião dos sujeitos do estudo acerca das atividades de extensão que a universidade poderia realizar, foi possível coletar material para a realização do Quadro 3.

Primeira IC dos moradores das comunidades (Quadro 3): "Fazer mais atendimento". A questão da assistência está mais uma vez bastante presente na fala dos moradores das comunidades: “[...] a universidade poderia fazer mais atendimento, dá mais assistência para os moradores da comunidade na unidade de saúde [...]".

A extensão, sob a perspectiva de uma visão apenas assistencialista, acaba por impor o conhecimento à comunidade, descartando-lhe a possibilidade de desenvolver o seu próprio conhecimento. Nessa situação, o cidadão 


\section{Quadro 3}

Expressões-chave, Ideia central e Discurso do Sujeito Coletivo

de vinte e seis moradores das comunidades. Fortaleza-CE, Brasil, 2009

\section{Quais as ações de extensão que a universidade poderia estar realizando neste espaço?}

\section{Expressões-chave (1)}

"[...] pra mim a melhor coisa

seria fazer mais atendimento

$$
[\ldots]^{\prime \prime}
$$

"[...] bem que a universidade poderia aumentar os atendimentos e dá mais assistência [...]"

“[...] eu queria que fizessem mais consultas pros moradores da comunidade, pra diminuir as filas [...]"

"[...] se tivesse mais atendimento, a gente não teria que esperar tanto tempo por uma consulta, quando a gente fica doente [...]"

\section{Expressões-chave (2)}

“[...] eu ficaria muito agradecida se a universidade diminuísse a violência [...]" "[...] acho que poderia tentar algo pra diminuir a nossa violência, aqui tá muito perigoso, devido às drogas, tem droga demais, a gente até fica com medo de sair

$$
\text { [...]" }
$$

"[...] acho que poderia diminuir a violência, se a universidade se aproximasse mais da comunidade com algumas ações [...]"

\section{Discurso do Sujeito Coletivo (1)}

Acho que a universidade poderia fazer mais atendimento, dá mais assistência para os moradores da

\section{comunidade na unidade de saúde, diminuindo as filas. A gente fica doente e tem que esperar muito tempo por uma consulta. \\ Fazer mais atendimento.}

Discurso do Sujeito Coletivo (2) Acho que poderia tentar diminuir a violência, aqui tá muito perigoso principalmente devido às drogas, a gente fica com medo de sair. Se a universidade se aproximasse mais da comunidade com algumas ações, acho que a violência poderia diminuir. 


\section{Quadro 3}

Continuação...

Quais as ações de extensão que a universidade poderia estar realizando neste espaço?

\begin{tabular}{|c|c|c|}
\hline $\begin{array}{c}\text { Expressões-chave (3) } \\
\text { “[...] poderia ter mais } \\
\text { atividades de educação em } \\
\text { saúde [...]" } \\
\text { “[...] quanto mais atividade } \\
\text { de educação em saúde } \\
\text { melhor, pois aqui às vezes } \\
\text { passa mais de um mês sem } \\
\text { nenhuma atividade [...]” } \\
\text { “[...] acho que continuar } \\
\text { com atividades sobre saúde, } \\
\text { porque a gente sabe que a } \\
\text { população daqui é bastante } \\
\text { carente sobre informações de } \\
\text { saúde [...]” }\end{array}$ & $\begin{array}{c}\text { Ideia Central (3) } \\
\text { Mais atividades de educação } \\
\text { em saúde. }\end{array}$ & $\begin{array}{l}\text { Discurso do Sujeito Coletivo (3) } \\
\text { Eu acho que mais atividades de } \\
\text { educação em saúde, pois às vezes } \\
\text { chega a passar mais de um mês } \\
\text { sem nenhuma atividade com a } \\
\text { comunidade e a gente sabe que a } \\
\text { nossa população é bastante carente } \\
\text { de informações sobre saúde. }\end{array}$ \\
\hline $\begin{array}{l}\text { Expressões-chave (4) } \\
\text { „[...] poderia formar alguns } \\
\text { grupos de debates, discutir } \\
\text { assuntos que abordassem } \\
\text { temas de interesse da } \\
\text { comunidade [...]” } \\
\text { “[...] vejo que poderia tentar } \\
\text { chamar os moradores para } \\
\text { discutirem assuntos do } \\
\text { cotidiano deles como drogas, } \\
\text { sexualidade e escolha da } \\
\text { profissão [...]” } \\
\text { “[...] acho que poderia } \\
\text { estimular os moradores } \\
\text { de todas as idades para } \\
\text { conversar em grupo, } \\
\text { debatendo vários temas } \\
\text { importantes [...]” }\end{array}$ & $\begin{array}{c}\text { Ideia Central (4) } \\
\text { Formação de grupos de } \\
\text { debates. }\end{array}$ & $\begin{array}{c}\text { Discurso do Sujeito Coletivo (4) } \\
\text { A formação de grupos de debates } \\
\text { que abordassem assuntos de } \\
\text { interesse da própria comunidade, } \\
\text { como drogas, sexualidade e escolha } \\
\text { da profissão, envolvendo moradores } \\
\text { de todas as idades, estimulando-os } \\
\text { para essas discussões. }\end{array}$ \\
\hline
\end{tabular}




\section{Quadro 3 \\ Continuação...}

Quais as ações de extensão que a universidade poderia estar realizando neste espaço?

\begin{tabular}{|c|c|c|}
\hline $\begin{array}{c}\text { Expressões-chave (5) } \\
\text { "[...] eu estou tentando } \\
\text { escolher pra que vestibular } \\
\text { eu vou fazer, só que eu não } \\
\text { tenho muito conhecimento, } \\
\text { assim a universidade poderia } \\
\text { discutir um pouco sobre } \\
\text { profissões [...]” } \\
\text { “[...] nós não sabemos muito } \\
\text { sobre o que cada profissão } \\
\text { faz, assim poderia se criar } \\
\text { umas discussões com os } \\
\text { estudantes daqui sobre as } \\
\text { funções de cada profissão } \\
\text { [...]" } \\
\text { “[...] gostaria de fazer uma } \\
\text { boa escolha para a minha } \\
\text { futura profissão, mas antes a } \\
\text { universidade poderia vim aqui } \\
\text { fazer algumas orientações } \\
\text { pra gente [...]” }\end{array}$ & $\begin{array}{c}\text { Ideia Central (5) } \\
\text { Discussão sobre profissões. }\end{array}$ & $\begin{array}{c}\text { Discurso do Sujeito Coletivo (5) } \\
\text { Gostaria que realizassem atividades } \\
\text { de discussão sobre profissões, } 0 \\
\text { pessoal da universidade poderia vir } \\
\text { discutir o que cada profissão faz. } \\
\text { Porque assim poderíamos direcionar } \\
\text { as nossas futuras escolhas } \\
\text { profissionais. }\end{array}$ \\
\hline
\end{tabular}

torna-se objeto de uma ação, um ser meramente passivo, desconhecendo-se como sujeito. Essa ausência de diálogo leva a comunidade a um silêncio e não lhe oferece condições de desenvolvimento, num ato antidemocrático (BUFFA; CANALES, 2007).

Segunda IC dos moradores das comunidades (Quadro 3): "Diminuir a violência”. Um dos maiores problemas sociais do cotidiano brasileiro é citado na fala dos moradores das comunidades: "[...] aqui tá muito perigoso principalmente devido às drogas, a gente fica com medo de sair. Se a universidade se aproximasse mais da comunidade com algumas ações, acho que a violência poderia diminuir". A comunidade percebe e compreende, de acordo com a fala, que a universidade pode e tem o potencial de transformação 
social e que junto com a comunidade poderia desenvolver várias atividades, não para acabar, mas para procurar soluções para controlar a violência.

É preciso repensar o extensionismo universitário, em uma dimensão em que os discentes, docentes e a população sejam atores mais ativos e que um dos objetivos dessa interação seja a construção de uma sociedade de paz, mais justa, mais humana e mais feliz. Certamente essa é uma das grandes revoluções de que se necessita hoje (ROCHA, 2001).

Percebe-se uma aproximação entre a terceira, quarta e quinta IC (Quadro 3): "Mais atividades de educação em saúde"; "Formação de grupos de debates" e "Discussão sobre profissões".

A proposta para a realização de atividades educativas refere-se à importância de considerar a capacidade do sujeito para organizar seu próprio processo de aprendizagem e de construir seu conhecimento, já que ensinar é criar as possibilidades para a construção e reconstrução de saberes. Assim, a universidade e a comunidade juntas construiriam o processo de educação. Nesse sentido, não haveria transmissão de conhecimentos, mas sim um diálogo, que possibilitasse desvelar dúvidas relativas a um determinado tema, como saúde, violência, escolha profissional, entre outros. Para realizar a educação popular de forma efetiva é fundamental permanecer em contato direto com as pessoas que farão parte do processo educativo, para melhor compreender o contexto e a cultura em que elas estão inseridas, facilitando, portanto, a troca de saberes (FREIRE, 1983).

Nessa perspectiva, as atividades educativas não se restringem a uma mera transferência de conhecimentos sobre determinado assunto, mas sim a troca de saberes entre a universidade e a comunidade, incluindo uma maior sensibilização sobre os temas abordados, a partir dos testemunhos de vida, que emergem ao longo do processo ensino-aprendizagem (FREIRE, 1983).

\section{DIFICULDADES ENFRENTADAS PELA UNIVERSIDADE PARA A REALIZAÇÃO DE ACִÕES DE EXTENSÃO}

Frente à questão das dificuldades enfrentadas pela universidade para o desenvolvimento de atividades, as seguintes ICs se apresentam no Quadro 4.

Primeira IC dos moradores das comunidades (Quadro 4): "Medo da violência". A violência está no centro do dia a dia e ocupa as manchetes 
dos jornais. Ela é um assunto que assombra as consciências, de tal forma que é ameaçadora, recorrente e geradora de um profundo sentimento de insegurança, o que acaba dificuldade uma aproximação mais efetiva da universidade com as comunidades circunvizinhas (CHESNAIS, 1999).

A segunda IC (Quadro 4) aborda: "Pouco interesse da universidade". Diferentemente da pesquisa, a extensão não oferece aos membros da comunidade acadêmica um status elevado como possuem os pesquisadores. Essa situação faz com que muitos docentes e discentes não se sintam atraídos em desenvolver atividades extensionistas. Outro aspecto que também contribui para esta falta de interesse pela extensão é a ausência de recursos oriundos de órgãos financeiros, que só destinam financiamento para projetos de pesquisa. Essa falta de recursos é um grande obstáculo para que docentes e discentes não se engajem em projetos que não podem ser

\section{Quadro 4}

Expressões-chave, Ideia central e Discurso do Sujeito Coletivo de vinte e seis moradores das comunidades. Fortaleza-CE, Brasil, 2009

\section{Quais as dificuldades de realização das ações de extensão?}

\begin{tabular}{|c|c|c|}
\hline $\begin{array}{c}\text { Expressões-chave (1) } \\
\text { "[...] deve ser devido à } \\
\text { violência, o pessoal fica com } \\
\text { medo [...]" } \\
\text { "[...] aqui tem muita droga e } \\
\text { roubo, assim os estudantes e } \\
\text { professores nem andam por } \\
\text { aqui [...]" }\end{array}$ & $\begin{array}{l}\text { Ideia Central (1) } \\
\text { Medo da violência. }\end{array}$ & $\begin{array}{l}\text { Discurso do Sujeito Coletivo (1) } \\
\text { Como aqui tem muita droga e } \\
\text { roubo, os estudantes e professores } \\
\text { da universidade ficam com medo, ai } \\
\text { eles nem andam por aqui. }\end{array}$ \\
\hline $\begin{array}{c}\text { Expressões-chave (2) } \\
\text { "[...] num sei, mas acho que } \\
\text { a universidade possui pouco } \\
\text { interesse, não tem vantagem } \\
\text { pra ela [...]" } \\
\text { "[...] a universidade num tem } \\
\text { é interesse mesmo [...]" } \\
\text { "[...] a universidade quer é } \\
\text { benefício pra ela, isso ela } \\
\text { não consegue aqui, assim ela } \\
\text { prioriza atividades dentro da } \\
\text { própria universidade [...]" }\end{array}$ & $\begin{array}{l}\text { Ideia Central (2) } \\
\text { Pouco interesse da } \\
\text { universidade. }\end{array}$ & $\begin{array}{l}\text { Discurso do Sujeito Coletivo (2) } \\
\text { Pode ser que a universidade possui } \\
\text { pouco interesse em realizar ações } \\
\text { na comunidade, não vendo nenhuma } \\
\text { vantagem e em realizar essas } \\
\text { ações. Pode ser que priorizem } \\
\text { mais atividades dentro da própria } \\
\text { universidade, que poderá lhe trazer } \\
\text { mais benefícios. }\end{array}$ \\
\hline
\end{tabular}




\section{Quadro 4 \\ Continuação...}

Quais as dificuldades de realização das ações de extensão?

Expressões-chave (3)
"[...] às vezes os próprios
moradores não demonstram
interesse pelas atividades da
universidade [...]"
“[...] tem morador que não se
interessa, demonstra muita
dificuldade em comparecer,
por exemplo, na questão da
educação em saúde o que a
gente vem notando é que são
realizadas algumas atividades
pelos estudantes, mas no
dia marcado são poucos os
moradores que comparecem
[...]”
“[...] os estudantes da
universidade convidam
os moradores para as
atividades, mas eles não
demonstram interesse [...]”

implementados pela ausência de recursos. Outro empecilho é a dificuldade de comunicação entre a Pró-reitoria de extensão, coordenação de cursos, docentes e discentes sobre a proposta e funcionamento da extensão na universidade (MONTE, 2005).

Ainda sobre a falta de interesse por parte da universidade em realizar atividades extensionistas, podemos citar: o tratamento que ela recebe no próprio contexto da universidade que elege como prioridade o ensino e a pesquisa, relegando para um plano secundário as atividades extensionistas; a falta de divulgação da extensão nos cursos da universidade; a falta de recursos financeiros para a elaboração e execução de projetos; e a ausência da extensão nos currículos dos cursos (CARBONARI; PEREIRA, 2007).

A terceira IC (Quadro 4): "A ausência de interesse dos próprios moradores". Destaca-se na fala dos moradores o seguinte trecho: “[...] são realizadas algumas atividades de educação em saúde pelos estudantes da 


\section{Quadro 5}

Expressões-chave, Ideia central e Discurso do Sujeito Coletivo de vinte e seis moradores das comunidades. Fortaleza-CE, Brasil, 2009

Quais as facilidades de realização das ações de Extensão?

\begin{tabular}{|c|c|c|}
\hline $\begin{array}{l}\text { Expressões-chave (1) } \\
\text { "[...] a facilidade é a } \\
\text { localização [...]" } \\
\text { “[...] aqui é muito próximo da } \\
\text { universidade [...]" } \\
\text { “[...] por ser muito próximo é } \\
\text { muito bom, para desenvolver } \\
\text { atividades aqui [...]" }\end{array}$ & $\begin{array}{c}\text { Ideia Central (1) } \\
\text { A localização. }\end{array}$ & $\begin{array}{l}\text { Discurso do Sujeito Coletivo (1) } \\
\text { Acho que a maior facilidade é a } \\
\text { nossa localização, aqui é muito } \\
\text { próximo da universidade, o que } \\
\text { é muito bom para desenvolver } \\
\text { atividades aqui na nossa } \\
\text { comunidade. }\end{array}$ \\
\hline $\begin{array}{c}\text { Expressões-chave (2) } \\
\text { "[...] aqui têm espaço físico } \\
\text { muito bom [...]" } \\
\text { "[...] a comunidade tem } \\
\text { espaços favoráveis e abertos } \\
\text { para a universidade, como } \\
\text { o colégio e a unidade saúde } \\
\text { [...]" } \\
\text { “[...] tanto a unidade saúde } \\
\text { quanto o colégio têm } \\
\text { estrutura para desenvolver } \\
\text { várias ações [...]" }\end{array}$ & $\begin{array}{l}\text { Ideia Central (2) } \\
\text { Espaço favorável. }\end{array}$ & $\begin{array}{l}\text { Discurso do Sujeito Coletivo (2) } \\
\text { A nossa comunidade possui } \\
\text { espaço favorável e aberto para } \\
\text { a universidade, como o colégio } \\
\text { e a unidade de saúde, que têm } \\
\text { estrutura para desenvolver várias } \\
\text { ações. }\end{array}$ \\
\hline
\end{tabular}

universidade, eles solicitam a presença da comunidade, mas no dia marcado, normalmente são poucos os moradores que comparecem [...]”. A universidade, atualmente, realiza poucas atividades na comunidade e, infelizmente, a baixa participação popular nessas ações acaba por desestimular ainda mais a universidade, levando os docentes e discentes a não mais desenvolver atividades na comunidade (MONTE, 2005).

\section{FACILIDADES ENFRENTADAS PELA UNIVERSIDADE PARA A REALIZAÇÃO DE AC̣ÕES DE EXTENSÃO}

O material coletado, com relação às facilidades enfrentadas pela universidade para o desenvolvimento de atividades, forneceu conteúdo para o desenvolvimento das ICs demonstrada no Quadro 5. 
As ICs convergem para o mesmo assunto: "A localização" e "Espaço favorável". Portanto, a comunidade, por possuir espaços com uma adequada estrutura física, como colégios e unidades básicas de saúde, e uma localização bastante favorável para o acesso dos docentes e discentes, fatores importantes para facilitar o desenvolvimento de atividades pela universidade dentro das comunidades, acaba desenvolvendo, assim, laços mais fortes de parceria.

\section{CONSIDERACְÕES FINAIS}

Percebe-se no estudo que a relação que a universidade possui com as comunidades circunvizinhas ainda é bastante limitada, sendo, às vezes, restrita a atividades assistenciais e como campo de estágio das aulas teóricas. Nota-se também, ainda, que a universidade possui um grande potencial de transformação social e pode ser compreendida como um ambiente de formação de profissionais cidadãos, com capacidade de construir atividades voltadas para melhorias da qualidade de vida da sociedade.

A extensão universitária possui ainda uma função essencial no ensino superior brasileiro, tanto para o aperfeiçoamento dos discentes, quanto para o processo de formação continuada dos docentes, para que ambos busquem uma maior integração com os demais setores da sociedade, melhorias na qualidade de vida dos moradores das comunidades circunvizinhas e para que as lutas sociais se fortaleçam, contribuindo, assim, com a construção de um pensamento crítico e colaborando para que o homem possa escrever a sua própria história.

Atualmente há alguns projetos, na universidade em que se desenvolveu a pesquisa, que tentam trabalhar em parceria com as comunidades circunvizinhas, como é o caso da Web Radio e do Programa de Educação para o Trabalho (PET) em Saúde.

O primeiro é um veículo de comunicação e informação, via internet, que cumpre uma função de socialização do conhecimento em saúde e cidadania, trabalhando com assuntos solicitados pela própria comunidade, como prevenção de doenças sexualmente transmissíveis, dengue, gravidez na adolescência, entre outros. 
O segundo agrega estudantes dos diversos cursos da área da saúde com o objetivo de trabalhar o empoderamento dos moradores, ou seja, criam condições para que os próprios moradores se tornem capazes de construir soluções para os problemas identificados na comunidade. Um dos casos mais recentes da articulação do PET saúde com a comunidade foi a criação de um conselho de saúde que não existia naquela localidade.

Entende-se, por fim, que todos os resultados de uma pesquisa são provisórios e novos estudos sobre a temática precisam ser feitos e aprofundados. Em especial referente à elaboração de estratégias para uma maior aproximação entre a universidade e a comunidade, rompendo com as ações pontuais e fragmentadas, buscando a construção de atividades contínuas e com participação direta dos moradores das comunidades no seu planejamento e organização. Esses são pontos que merecem ser considerados em estudos futuros. 


\section{REFERÊNCIAS}

BRASIL. Conselho Nacional de Saúde. Resolução n 196/96. Decreto no. 93.933 de janeiro de 1987. Estabelece critérios sobre pesquisa envolvendo seres humanos. Bioética, Brasilia, v. 4, n. 2, p. 15-25, 1996. Suplemento.

BRASIL. Ministério da Educação e do Desporto. Plano Nacional de Extensão Universitária. Brasília: MEC/CRUB, 1999. Documento do Fórum Nacional de Pró-Reitores de Extensão das Universidades Públicas Brasileiras.

BUFFA, E.; CANALES, P. R. Extensão: meio de comunicação entre universidade e comunidade. EccoS Revista Científica, São Paulo, v. 9, n.1, p. 157-169, jan./jun. 2007.

CARBONARI, M. E. E.; PEREIRA, A. C. A extensão universitária no Brasil, do assistencialismo à sustentabilidade. Revista de Educação, Itatiba, v. 10, n. 10, p. 23-28, 2007. CHESNAIS, J. C. A violência no Brasil: causas e recomendações políticas para a sua prevenção. Ciência \& Saúde Coletiva, Rio de Janeiro, v. 4, n. 1, p. 53-69, 1999. http:/ /dx.doi. org/10.1590/S1413-81231999000100005

FONTANELLA, B. J. B.; RICAS, J.; TURATO, E. R. Amostragem por saturação em pesquisas qualitativas em saúde: contribuições teóricas. Cadernos de Saúde Pública, Rio de Janeiro, v. 24, n. 1, p. 17-27, jan. 2008. http://dx.doi.org/10.1590/S0102-311X2008000100003 FÓRUM DE PRÓ-REITORES DE EXTENSÃO DAS UNIVERSIDADES PÚBLICAS BRASILEIRAS - FORPROEX, 2010, Belo Horizonte. Extensão Universitária: organização e sistematização. Belo Horizonte: COOPMED, 2010.

FREIRE, P. Educação como prática da liberdade. 2. ed. Rio de Janeiro: Paz e Terra, 1969. p. 150. FREIRE, P. Educação e Mudança. Rio de Janeiro: Paz e Terra, 1979.

FREIRE, P. Pedagogia do Oprimido. Rio de Janeiro: Paz e terra, 1983.

FREIRE, P. Extensão ou comunicação? 10. ed. Rio de Janeiro: Paz e Terra, 1992

GURGEL, R. M. Extensão Universitária: Comunicação ou domesticação? São Paulo: Cortez, 1986.

INSTITUTO BRASILEIRO DE GEOGRAFIA E ESTATÍSTICA - IBGE. Primeiros Resultados do CENSO 2010. Rio de Janeiro: IBGE, 2010. Disponível em: <http://www. censo2010.ibge.gov.br/>. Acesso em: 07 maio 2012.

LEFÈVRE, F.; LEFÈVRE, A. M. C. O discurso do sujeito coletivo: um novo enfoque em pesquisa qualitativa (desdobramentos). Caxias do Sul: Educs, 2005.

LIMA, C. L. D. C. O papel da extensão na universidade. Leopoldianum, Santos, v. 28, n. 78, p. 11-38, jun. 2003.

MELO NETO, J. F. Extensão universitária, autogestão e educação popular. João Pessoa: Ed. Universitária; UFPB, 2004. p. 210.

MENEZES NETO, P. E. Universidade: ação e reflexão. Fortaleza: Edições UFC; Imprensa Universitária, 1983. p. 233.

MINAYO, M. C. S. O desafio do conhecimento: pesquisa qualitativa em saúde. 10. ed. São Paulo: Hucitec, 2007.

MONTE, A. F. Reflexões sobre extensão e universidade no contexto atual. 2005. Monografia (Especialização em Docência do Ensino Superior)-Universidade Estadual do Ceará, Fortaleza, 2005. 
PAULA, K. A.; PALHA, P. F; PROT'TI S. T. Intersetorialidade uma vivência prática ou um desafio a ser conquistado? O discurso do sujeito coletivo dos enfermeiros nos núcleos de saúde da família do distrito oeste-Ribeirão Preto. Interface: Comunicação, Saúde e Educação, Botucatu, SP, v. 8, n. 15, p. 331-48, mar./ago. 2004.

PEREIRA, Q. L. C. et al. Processo de (re)construção de um grupo de planejamento familiar: uma proposta de educação popular em saúde. Texto \& Contexto Enfermagem, Florianópolis, v. 16, n. 2, p. 320-5, jun. 2007. http://dx.doi.org/10.1590/S0104-07072007000200016

ROCHA, R. M. G. A Construção do Conceito de Extensão Universitária na América Latina. In: FARIA, D. S. (Org.). Construção Conceitual da Extensão Universitária na América Latina. Brasília: UnB, 2001.

SARAIVA, J. L. Papel da Extensão Universitária na Formação de Estudantes e Professores. Brasilia Médica, Brasília, v. 44, n. 3, p. 220-225, 2007.

SAVIANI, D. Extensão universitária: uma abordagem não-extensionista. Educaşão e Sociedade, São Paulo, n. 8, p. 61-73, mar. 1981.

TREZZA, M. C. S. F.; SANTOS, R. M.; SANTOS, J. M. Trabalhando educação popular em saúde com a arte construída na cotidiano da enfermagem: um relato de experiência. Texto \& Contexto Enfermagem, Florianópolis, v. 16, n. 2, p. 326-34, jun. 2007. http:/ /dx.doi. org/10.1590/S0104-07072007000200017

Recebido: 25/04/2011

Aprovado: $14 / 06 / 2012$

Contato:

Universidade Estadual do Ceará

Centro de Ciências da Saúde Av. Paranjana, 1700, Campus do Itaperi

CEP 60740-000 Fortaleza, CE

Brasil 